\title{
The Low-Carbon Operations in Ecotourism Service Supply Chain Management
}

\author{
Shang-Yu Liu \\ National Kaohsiung University of Hospitality and Tourism, Kaohsiung, Taiwan \\ Meiho University, Pingtung, Taiwan \\ Wei-Shuo Lo \\ Meiho University, Pingtung, Taiwan
}

\begin{abstract}
The ecotourism has quickly developed as the fastest growing industry in recent years. Ecotourism is one kind of tourism industry that also consists of complex service providers like travel agents, hotels, transportations (such as airplane, bus, and ship) restaurants, and destinations, connecting with operational diversity; therefore, those of supported services are linked with a supply chain together, and its management is called ecotourism service supply chain management (ESSCM). Moreover, a low-carbon operation management has also become an important challenge to ecotourism nowadays. Based on the problems of service and low-carbon operation management made together above, exploring an effective solution into ecotourism is worthy. Using ESSCM as a strategy for solving industrial problems of service and low-carbon operations management in ecotourism is explored in this paper. The contributions here include clearly explanations of what ESSCM is and how ESSCM is used with low-carbon operations as a sustainability strategy, and finally a practical case study is also examined in the end.
\end{abstract}

Keywords: ecotourism, low-carbon, operations, supply chain management, services

\section{Introduction}

The term of low-carbon operations is that $\mathrm{CO}_{2}$ emissions can be reduced in all world regions and sectors (Knopf, Edenhofer, Flachsland, Kok, Lotze-Campen, Luderer, Popp, \& Van Vuuren, 2010). The concept of low-carbon operations is the prevention of "dangerous" climate change and environmental sustainability (Darnall, Jolley, \& Handfield, 2008). This is concerned not only with the issue of environment, but also considered the whole industries on how to operate without more $\mathrm{CO}_{2}$ emissions. Therefore, the low-carbon operation management has become an important challenge for different industries nowadays.

Darnall et al. (2008) thought that an organization's direct environmental impacts stem from inputs increasing waste during product storage, transportation, processing, use or disposal. This means that business production process of products is across different operational procedures. These operational procedures consist

Shang-Yu Liu, Ph.D. student, The Graduate Institute of Travel and Tourism Management, National Kaohsiung University of Hospitality and Tourism; Lecturer, Department of Hospitality Management, Meiho University. Email: kurisuyui@gmail.com; x00003526@meiho.edu.tw.

Wei-Shuo Lo, Assistant Professor, Department of Hospitality Management, Meiho University.

Correspondence concerning this article should be addressed to Wei-Shuo Lo, Meiho University, 23, PingKuang Rd., Neipu, Pingtung 91202, Taiwan, R.O.C. Email: x2134@meiho.edu.tw. 
of different stakeholders, like raw material suppliers, manufacturers, wholesalers, retailers, and then customers. Several stages are from upstream to downstream of an industrial supply chain. However, supply chain management does not only apply to manufacturing industry, but also the concept and method can be used to the service industry (Kathawala \& Abdou, 2003). The problems of information and logistics in "fashion" industry are explained by Lo and Hong (2012), a kind of service industry, in which the supply chain management has faced the problems of a six-phase information management. The six phases are as follows:

(1) Collecting information: A data collection mechanism or an information system should be used to collect daily transaction data;

(2) Storing information: Software or a database management system should be adopted to store transaction data;

(3) Integrating information: Different data should be integrated together from different databases;

(4) Analyzing information: Analytical software is used to analyze datasets;

(5) Explaining information: Analytical results are explained to aid in decision-making;

(6) Delivering information: Shared information is delivered to business partners based on their requirements.

The other problems in a supply chain are logistics, relating to three main activities including supply, operation, and distribution as follows:

(1) Supply: It is concerned with the tasks of sourcing, purchasing, and transporting raw materials, handling parts inventory, and making effective deliveries. This part is called inbound logistics;

(2) Operation: It mainly conducts the processes of production with agile approaches. Its tasks include production planning, production scheduling, and process inventory;

(3) Distribution: It focuses on satisfying customer requirements. Among its tasks of forecasting, customer service, finished goods inventory, warehousing, and transportation, this part is also called outbound logistics.

As problems mentioned above including information and logistics in service industry of fashion, we know that only "customer service" is proposed as a service issue in the stage of distribution. However, tourism industry is more difficult to manage than fashion industry. Especially, ecotourism is one kind of tourism industry that also consists of complex service providers such as travel agents, hotels, transportations (airplanes, buses, and ships are included) restaurants, and destinations connecting with operational diversity. Therefore, those of supported services are linked with a supply chain together, and its management is also called ESSCM.

Based on the problems of service and low-carbon operation management mentioned above, exploring a sustainable solution into ecotourism is worthy. The problem is explored in this paper by using ESSCM as a strategy for solving problems of the service industry and low-carbon operation management in ecotourism. The contributions here include clearly explanations of what ESSCM is and how ESSCM is used with low-carbon operations as a sustainable strategy.

This paper is divided into five sections. The first section reviews some important literatures. The second section introduces the service supply chain management of tourism industry. The third section provides a low-carbon operation for ecotourism service supply chain. A practical case study is explored in the fourth section to explain the findings of this study. Finally, the conclusions, discussions, study limitations, and future implications are also described in the last section of this paper. 


\section{Tourism Service Supply Chain Management}

This section discusses what the tourism industry and its service supply chain are. According to Bhatia (2006), tourism consists of various components including accommodation, transport, attractions, and support services. The support services include both private and public sectors. The whole tourism industry structure has been shown in Figure 1.

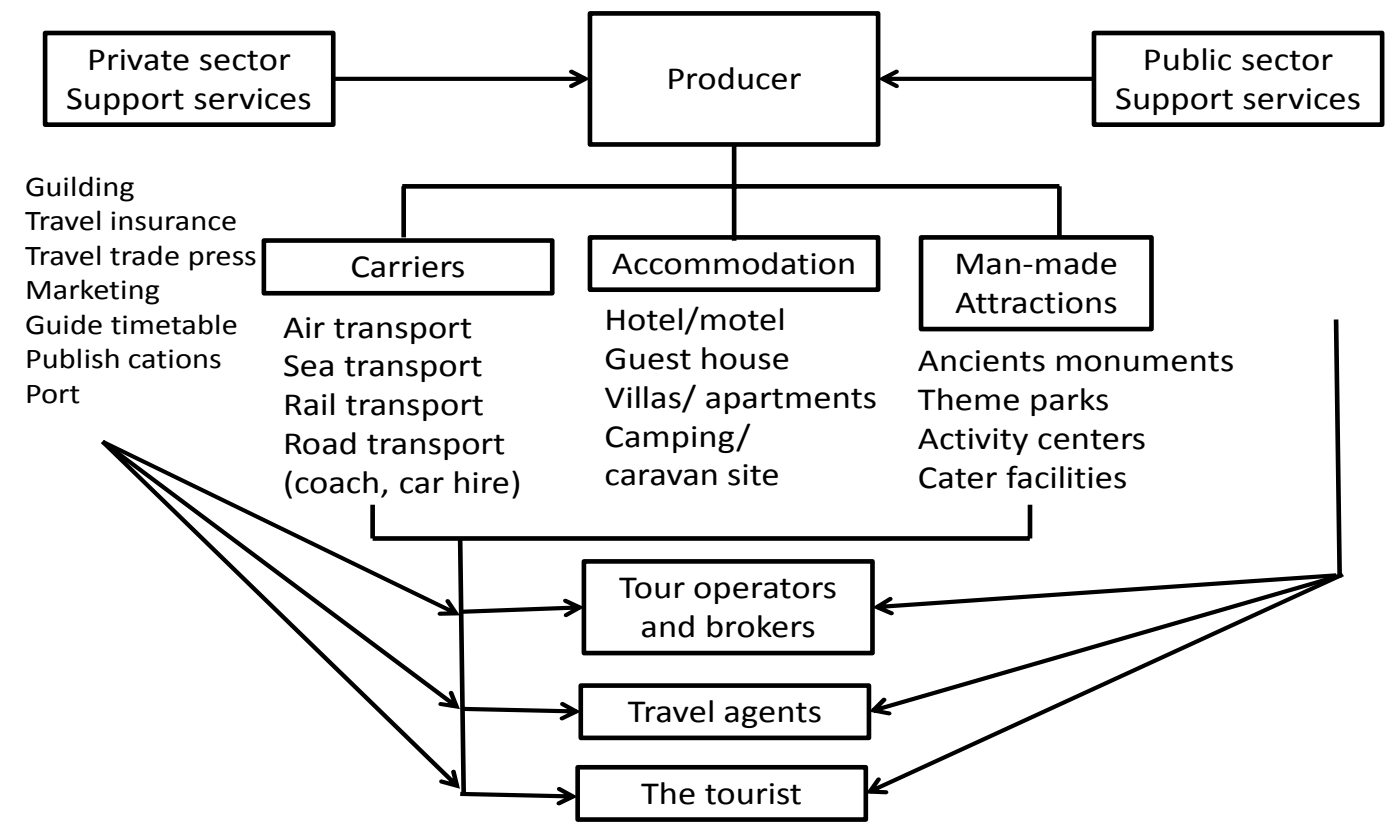

Figure 1. The tourism industry structure (Bhatia, 2006).

In the tourism industry structure, we find that tourism industry consists of different supported services. These supported services include travel insurance, travel trade press, and marketing, etc., which are cooperated as tourism products for tourists' needs. These supported services should be offered by different featured service providers, here also are the same as manufacturing suppliers from upstream supply chain of the industry, and becoming more complex operations and networks. Therefore, according to Clancy (1998), supported services of tourism not only constitute the largest service industry in the world, but also account for the single largest service item in international trade of services. Based on the abovementioned, we find that service supply chain thus recognized that working with different stoke holds in the tourism industry.

Why do the services play an important role in the whole industrial supply chain? The answer is that the supply chain management is the integration of key business process to end users through original suppliers offering services and information, adding value for customers and the other stakeholders (Lambert, Cooper, \& Pagh, 1998). Wu and Yang (2009) described the concept of supply chain management into tourism industry; therefore, the tourism supply chain is defined to response with different services to relevant customer's needs such as transportation service, catering service, hotel service, and relaxing service. Therefore, tourists, tour operators, and service suppliers constitute a complete tourism supply chain.

In short, service adds value for customers and other stakeholders in the tourism supply chain; therefore, we think that a tourism service supply chain management, according to the abovementioned, can be drawn as Figure 2. And the whole operational stakeholders are included as below: 


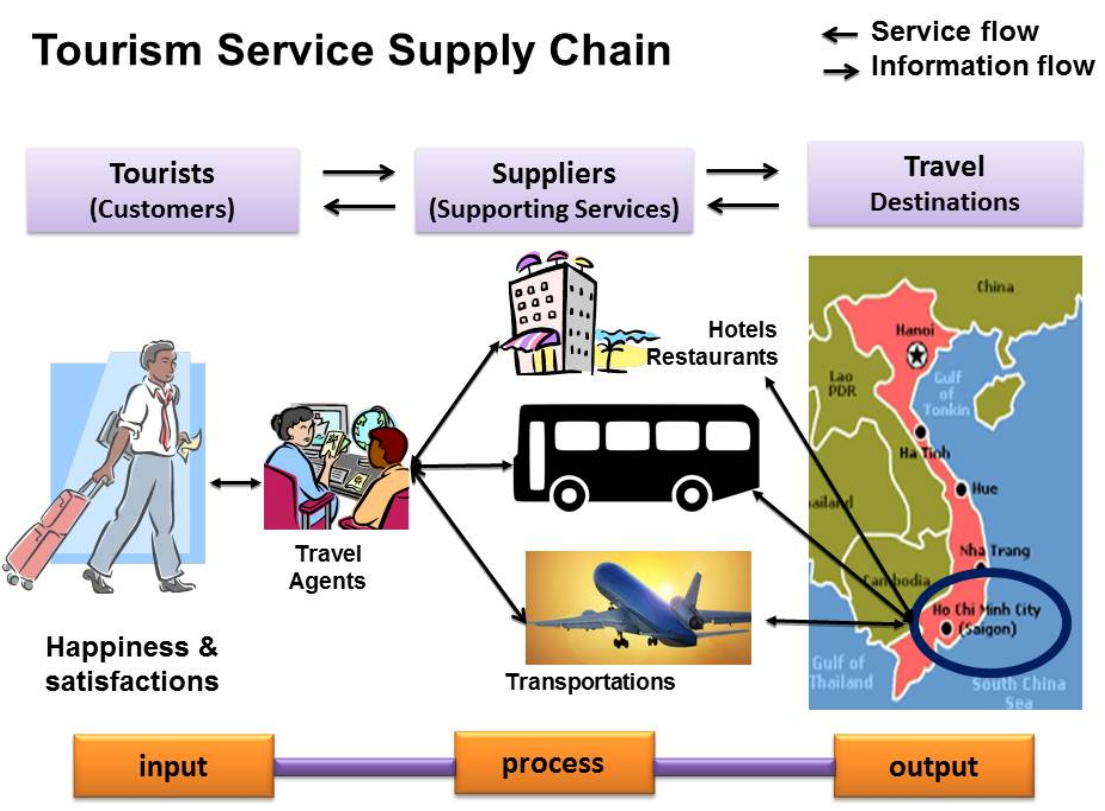

Figure 2. Tourism service supply chain management (traditionally).

(1) Input: tourists (customers), suppliers (supporting services), and travel destinations;

(2) Process: two flows of service and information should be included: complex operations of provision and management. The information flow starts from downstream of supply chain as tourists (customers) needs. Then, the information is delivered to suppliers (supporting services) such as travel agents, or through website contacts of hotels, restaurants, attraction of destinations, and airlines (transportations);

(3) Output: this is the good feeling of tourists (customers) such as happiness or satisfaction when their travel is completed. The industry receives the business profits and approaches the managerial performances as well as sustainable business operations.

\section{The Low-Carbon Operations and Service Supply Chain Into Ecotourism}

The term of low-carbon operations is that $\mathrm{CO}_{2}$ emissions can be reduced in all world regions and sectors. The low-carbon operations prevent climate change and environmental sustainability. Therefore, reducing $\mathrm{CO}_{2}$ emissions has become an important task for industries and businesses.

However, sometimes a gap exists between the theory and the real life since practical operations face dynamic uncertainties. Especially, there are complex and different services operations interacting from upstream to downstream, the ecotourism or tourism is just one of them.

Bhatia (2006) proposed that tourism industry increases the concern on green issue of environmental quality of destinations, better services both in their own country and in a host country are also value for money. This idea is also fit for a concept that customers should be involved in sustainable supply chain management in tourism provided by Sigala (2014).

This involves the following four dimensions: factors motivating customer involvement in sustainability, the degree of customer involvement, management strategies for customer involvement, and outcomes of customer involvement. 
Why should the sustainable supply chain management in tourism consider customer involvement? The major reason relates to the operations in the whole tourism service supply chain management when services operated for customer's needs. So, low-carbon operations in ESSCM cannot make sense without customer's involvement. Low-carbon operations and production require employee training, because the service operations are operated by the first-line employee. And they present directly the quality of service operations to customers. Therefore, Jabbour and Jabbour (2014) suggested training subjects on three categories: low-carbon products, low-carbon production, and low-carbon logistics. Although training subjects of low-carbon operations and production management have been suggested by Jabbour and Jabbour (2014), we also found such perspective (Hsu, Kuo, Shyu, \& Chen, 2014). There are several useful criteria associated with carbon management in selecting suppliers in a hotel supply chain. The 12 criteria are included:

(1) Energy efficiency of products;

(2) Eco-labeling of products;

(3) Carbon accounting and inventory;

(4) Energy reduction of food processing;

(5) Carbon governance;

(6) Carbon policy;

(7) Carbon reduction targets;

(8) Carbon and energy management systems;

(9) Transport efficiency;

(10) Collaboration of suppliers;

(11) Carbon reduction and energy conservation measures;

(12) Food mile management.

In short, the ESSCM integrates two concepts into ecotourism which are low-carbon operations and service supply chain management as shown in Figure 3.

\section{Ecotourism Service Supply Chain $\stackrel{\leftarrow \text { Service flow }}{\rightarrow \text { Information flow }}$}

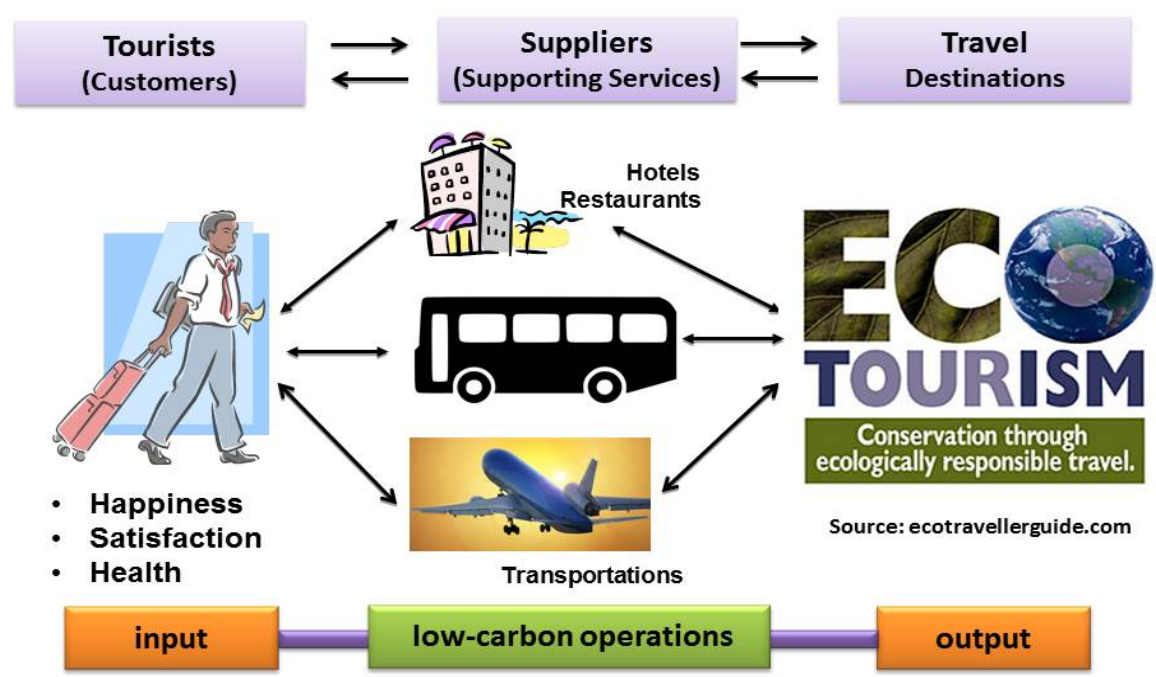

Figure 3. ESSCM with low-carbon operations. Source: http://www.ecotravellerguide.com/. 
Related tasks above are connected together with perspectives of customer and employee. This means that carbon management starts from supplier selection (Hsu et al., 2014), and then through hotel supply chain to the time when employees deliver services to customers, thus satisfaction is shaped by different kinds of services delivery. This procedure is a long process across different functions of operational management such as marketing, production, inventory, human resource, R\&D, and finance. Therefore, low-carbon operations are related to sustainable tourism development (Sharpley, 2009). There are three senses proposed as follows:

(1) As a goal or vision;

(2) As a process of achieving or moving towards that vision;

(3) As the policies, plans, and activities of those organizations, whether private or public or third sector.

Therefore, ESSCM is a critical sustainability (Saarinen, 2014) which is setting the responsibility in tourism. A practical case study is explained in the next section.

\section{A Practical Case Study}

The ecotourism has quickly developed as the fastest growing segment in the travel and tourism industry in recent years. There are several important impacts on the ecotourism which include economics, culture, society, environment, moderating, and ethics (Herbig \& O’Hara, 1997). To understand how the service quality impacts on ecotourism, Lo, Mohamad, Songan, and Yeo (2012) used a case study to explore tourists' needs when they travel to Bario. Based on knowing the reason of how and why, the research method of a case study was used to explore our questions too.

\section{Methodology}

The qualitative research method is used to determine how service supply chain management works with low-carbon operations in ecotourism. The reason is explained by Yin (2003) that a methodology of case study is preferred strategy for "how" or "why" questions. And the methodology is suitable to explore a situation in which the social context is unknown.

"How" or "why" questions have been asked about a contemporary set of events, over which the investigator has little or no control. A single case study is an appropriate design under several circumstances.

Base on a service strategy by Haksever, Render, Russell, and Murdick (2000) of how to implement it into an organization or company, this study raises a question here: How does a firm (travel destination) use supply chain with low-carbon operation management as a service strategy into ecotourism?

\section{Data Collection Phases}

Beeton (2005) proposed a multi-method case study as a qualitative research method to understand complex relationships and interactions. There are two phases used, including secondary data collection and self-reflexivity.

The first phase is to gather secondary data from the website of a studied firm (travel destination):

(1) Analyzing the contents to find which actions they are doing for ecotourism;

(2) The functions (service operations) made in operation management;

(3) This phase uses content analysis based on the data from the website of studied firm (travel destination).

The second phase is to find how and why - operation management as a service strategy:

(1) How have they done in the operation management?

(2) Why do they perform low-carbon operations within those of services? 
(3) Participation and observation used to collect the real data: (a) to participate in the field of travel destination; and (b) to observe and interview with hosts why they have done those things and whether they have known the reason.

\section{Analyzing Evidence}

After two-phase data collection, this study depends on Yin's (2003) method of analyzing evidence using a single case study. A time-series analytic technique is used to analyze evidence. The evidence is based on the records of activities from the case and then connected together with a sequence of time.

And a time-series analytic technique compared to a more general pattern-matching analysis can be much simpler in sense, and a single dependent or independent variable. An example is shown as in Tables 1, 2, and 3.

Table 1

A Time-Series Pattern

\begin{tabular}{|l|l|}
\hline Time series & Patterns \\
\hline July 1 & A, B, E \\
\hline July 2 & B, F, D \\
\hline July 3 & A, B, C \\
\hline
\end{tabular}

Table 2

\section{Patterns' Counting}

\begin{tabular}{ll}
\hline Patterns & Time's counting \\
\hline A (services) & 2 \\
B (process) & 3 \\
C (water) & 1 \\
D (sea) & 1 \\
E (food) & 1 \\
F (environment) & 1 \\
A, B & 2 \\
\hline
\end{tabular}

Table 3

A Pattern Bigger Than the Threshold is 2

\begin{tabular}{ll}
\hline Patterns & Time's counting \\
\hline A (services) & 2 \\
B (process) & 3 \\
A, B (services process) & 2 \\
\hline
\end{tabular}

Tables 1, 2, and 3 show collected patterns (data) used to analyze and explain the information. Then, the blind knowledge, therefore, can be explored. Here, the time series are containing the keyword (pattern) that we concerned and its frequency. Then pattern's sequences as well as patterns counted together. And finally, the useful analyzed information can explain the knowledge.

For example, the results shown in Table 3 are A (services), B (process), A and B (services process). This means that they are contented useful patterns from Table 2 which are services, process, water, sea, food, or environment. To integrate those of these analyzed patterns, we obtain enough information to build knowledge from a single case study. Continuing the above example, we can explain the qualitative content when the keywords are services, process, or services process. 


\section{Results}

A single case study is used to explore our question: How does a firm (travel destination) use supply chain with low-carbon operation management as a service strategy into ecotourism? The case is a travel destination named Pasikang Leisure Park. Our research is conducted by investigating a family about their ecotourism travel experience of Paiwan indigenous culture. The two-phase case study is used as follows:

The first phase is to gather secondary data from the website of the studied firm (travel destination) to find which actions they are doing for ecotourism by analyzing the website contents as shown in Figure 4.

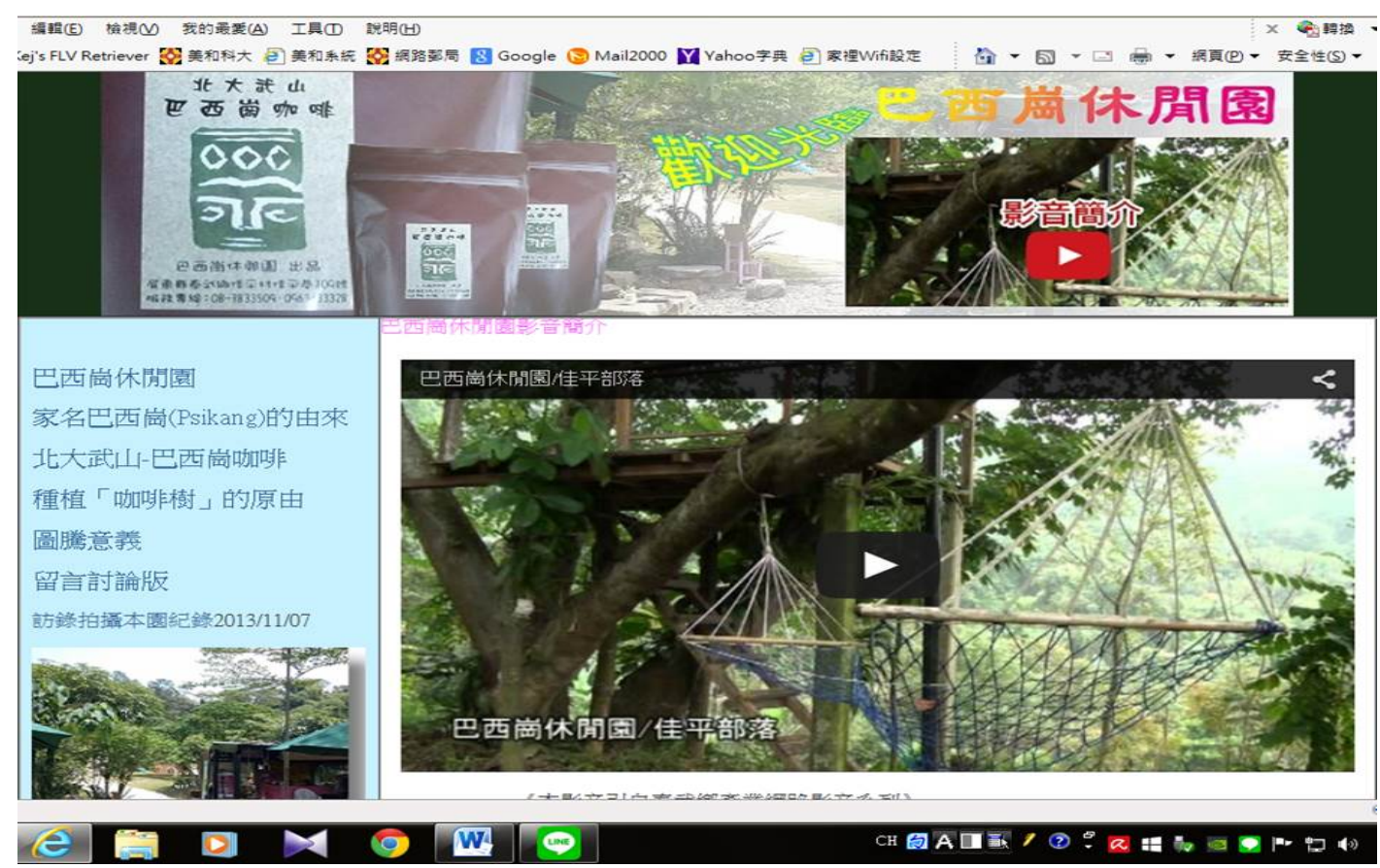

Figure 4. The homepage of Pasikang Leisure Park (in Chinese), Kaviyangan Tribe, Taiwu Township, Pingtung County, Taiwan. Source: http://paiwan.com.tw/pasikang/index.htm.

The contents of website include:

(1) Introduction to the background of Pasikang Leisure Park;

(2) Introduction to ecological environment and the living room of backpacker;

(3) The story of coffee trees at the North Dawu Mountain;

(4) The meaning of logo that is shown in Figure 5.

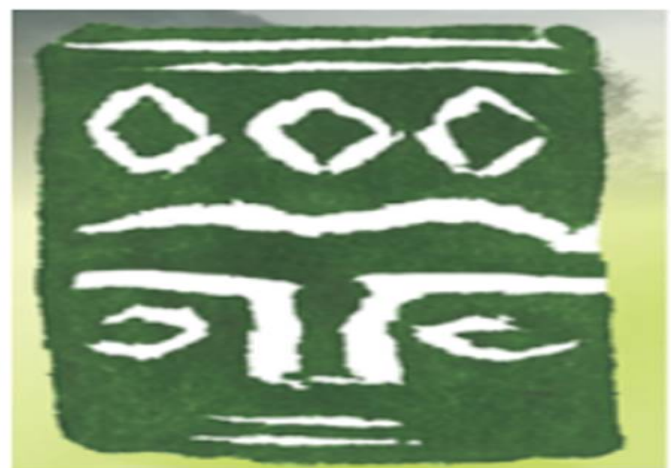

Figure 5. Logo of Pasikang Leisure Park (thanks God and ground). 
The functions (service operations) made in operations management are as follows:

(1) Indigenous cultural experience and interpretation;

(2) Ecological experience;

(3) Taste of black coffee;

(4) Living room of backpacker;

(5) Indigenous food.

The second phase is to find how and why - operation management considered as a service strategy:

(1) Pasikang Leisure Park, they have done after their operations within provided services;

(2) The low-carbon operations within different services have had to provide an indigenous culture, and the original living style is to preserve. For example, living room of backpacker without air-conditioners, not much light, cooking and eating local fresh agricultural produce as gifts of God;

(3) Participation and observation are used to collect the real data:

(a) To participate in the field of travel destination - Pasikang Leisure Park;

(b) To observe and interview with the host why they have done those things and whether they have known the reason. The participation and observation are described in Table 4.

\section{Table 4}

Participation and Observations With Time Series

\begin{tabular}{|l|l|l|}
\hline Time series & Photos & Participation and observations \\
\hline May 9, 2015 \\
8:00 pm
\end{tabular}


(Table 4 continued)

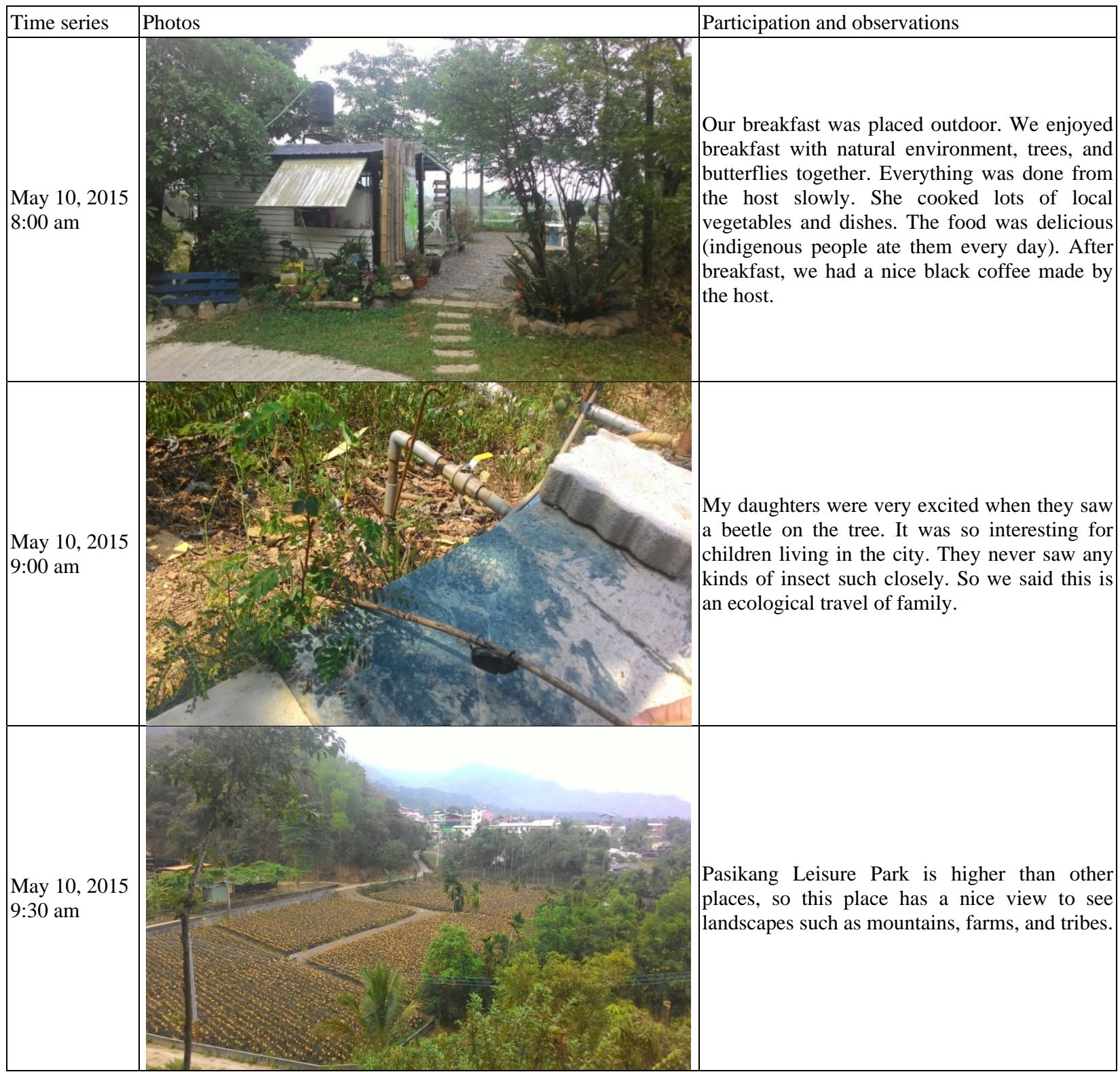

\section{Conclusions and Discussions}

This paper examines a concept indicating that customers should be involved in sustainable supply chain management of tourism (Sigala, 2014). We also explore the question: how does a firm (travel destination) apply a supply chain with low-carbon operation management as a service strategy into ecotourism? A single case study, Pasikang Leisure Park, is used, and we can find the answer after participation and observation. That is the ecotourism and sustainable tourism holding major potential for economic growth while proactively contributing to local quality of life and environment according to Gibson, Dodds, Joppe, and Jamieson (2003). The conclusions, discussions, limitations, and future implications are described below. 


\section{Conclusions}

The contributions of this paper consist of clearly explanation of what ESSCM is and how ESSCM can be used with low-carbon operations as a sustainable strategy, and finally a practical case study of Pasikang Leisure Park is also examined. Herbig and O’Hara (1997) proposed several important impacts on the ecotourism including economics, culture, society, environment, moderating, and ethics which are explained as follows:

(1) Economics: This paper shows that sustainable strategy will increase local economic and community revenue. The simple reason is that ecotourism makes people relaxed, thus attracting more tourists;

(2) Culture: In the case of Pasikang Leisure Park, we saw the Paiwan traditional indigenous culture in this ecotourism experience. We were living and eating with indigenous people together. To have the local food and enjoy the environment of original life was a wonderful experience;

(3) Society: We saw a different social relationship. The Pasikang Leisure Park's products and production are efforts of working with natural environment. However, sometimes they did not get enough income. Although they are not really rich, we saw that they felt happy enough about their life and the God's gifts. This shows the diversity of beliefs and society;

(4) Environment: We enjoyed breakfast in the natural environment with trees and butterflies together. The environment was beautiful and ecological diversity was also impressive;

(5) Moderating: Having experience of Pasikang Leisure Park, we discussed the experience (with my daughters) about the trip, their feelings were so interesting, since they have never touched the nature and saw a beetle on the tree such closely. This is a good opportunity to teach our students or children in protecting our environment for our unique earth. That is helpful and practical environmental education;

(6) Ethics: Sustainable strategy has focused on the issue of ethics in recent years. Ethics is important not only for local people but also for everyone. However, this is a challenge when people want to make money from the environment which damaged the ecological conservation. Ecotourism may raise a critical perspective on environmental conservations.

\section{Discussions}

Pasikang Leisure Park provides their services through website. Those useful information included are: the background of Pasikang Leisure Park, ecological environment and the living room of backpacker, the story of coffee tree in the mountain, and the meaning of logo. The information is useful for tourists before their trip.

The hospitality of Pasikang Leisure Park also promotes successfully the delivery of its services to customers. There are several impressions such as traditional indigenous cultural experience and interpretation, ecological experience, taste of black coffee, living room of backpacker, indigenous food. And those services almost are based on low-carbon operations such as:

(1) The water usage during a limited time for customers, and groundwater was also provided for the whole ecological environment by natural rainwater;

(2) The black coffee seeds were introduced and made by themselves. Through some of the process of farming at 900 meters above the sea level, it is growing in natural and ecological environment;

(3) There were no TVs and air-conditioners, no electronic devices added in the living room of the backpacker. There were only the natural wind and voices surrounding the whole living space;

(4) Indigenous food was friendly provided for breakfast in the morning. They do not have to purchase any kind of vegetables and agricultural products from traditional markets or supermarkets. They are gifts from the God. 
This is a natural, cultural, social, and educational experience of ecotourism service supply chain with low-carbon operation management. And this study also fits ecotourism: towards congruence between theory and practice (Ross \& Wall, 1999).

\section{Study Limitations}

This study is one case of Pasikang Leisure Park. The single case limits the evidence analyzed. Although we have enough data from two-phase analyzed process, a single case of a firm context may not be able to express for others.

\section{Future Implications}

We suggest that future study should involve more case studies or adapt different methodologies, or focus on different operations management of supply chain. Since ecotourism can explore different issues of economics, culture, society, environment, moderating and ethics. For example, Gibson et al. (2003) explored ecotourism in the city, his topic is interesting and Lee (2015) proposed green supply chain management (GSCM) on environmental and operational performances with a perspective of social capital accumulation in the supply chain.

\section{References}

Beeton, S. (2005). The case study in tourism research: A multi-method case study approach. In B. Ritchie, P. Burns, \& C. Palmer (Eds.), Tourism research methods: Integrating theory with practice (pp. 37-48). CAB International.

Bhatia, A. K. (2006). The business of tourism: Concepts and strategies. Sterling Publishers Pvt. Ltd..

Clancy, M. (1998). Commodity chains, services and development: Theory and preliminary evidence from the tourism industry. Review of International Political Economy, 5(1), 122-148.

Darnall, N., Jolley, G. J., \& Handfield, R. (2008). Environmental management systems and green supply chain management: Complements for sustainability? Business Strategy and the Environment, 17(1), 30-45.

Gibson, A., Dodds, R., Joppe, M., \& Jamieson, B. (2003). Ecotourism in the city? Toronto's green tourism association. International Journal of Contemporary Hospitality Management, 15(6), 324-327.

Haksever, C., Render, B., Russell, R. S., \& Murdick, R. G. (2000). Service management and operations (2nd ed.). UK: Prentice Hall.

Herbig, P., \& O’Hara, B. (1997). Ecotourism: A guide for marketers. European Business Review, 97(5), 231-236.

Hsu, C. W., Kuo, T. C., Shyu, G. S., \& Chen, P. S. (2014). Low carbon supplier selection in the hotel industry. Sustainability, 6(5), 2658-2684.

Jabbour, C. J. C., \& Jabbour, A. B. L. (2014). Low-carbon operations and production: Putting training in perspective. Industrial and Commercial Training, 46(6), 327-331.

Kathawala, Y., \& Abdou, K. (2003). Supply chain evaluation in the service industry: A framework development compared to manufacturing. Managerial Auditing Journal, 18(2), 140-149.

Knopf, B., Edenhofer, O., Flachsland, C., Kok, M. T. J., Lotze-Campen, H., Luderer, G., Popp, A., \& Van Vuuren, D. P. (2010). Managing the low-carbon transition - From model results to policies. The Energy Journal, 31(1), 223-245.

Lambert, D. M., Cooper, M. C., \& Pagh, J. D. (1998). Supply chain management: Implementation issues and research opportunities. The International Journal of Logistics Management, 9(2), 1-20.

Lee, S. Y. (2015). The effects of green supply chain management on the supplier's performance through social capital accumulation. Supply Chain Management: An International Journal, 20(1), 42-55.

Lo, M. C., Mohamad, A. A., Songan, P., \& Yeo, A. (2012). Repositioning strategy in the ecotourism industry: A case of Bario. Business Strategy Series, 13(1), 41-46.

Lo, W. S., \& Hong, T. P. (2012). A three-level multiple-agent early warning mechanism for preventing loss of customers in fashion supply chains. In Fashion supply chain management: Industry and business analysis (Chapter 9). IGI Global.

Ross, S., \& Wall, G. (1999). Ecotourism: Towards congruence between theory and practice. Tourism Management, 20(1), 123-132. 
Saarinen, J. (2014). Critical sustainability: Setting the limits to growth and responsibility in tourism. Sustainability, 6(1), 1-17. Sharpley, R. (2009). Tourism development and the environment: Beyond sustainability? London, UK: Earthscan.

Sigala, M. (2014). Customer involvement in sustainable supply chain management: A research framework and implications in tourism. Cornell Hospitality Quarterly, 55(1), 76-88.

Wu, H., \& Yang, S. (2009). Service supply chain: A conceptual framework compared with manufacturing supply chain. Proceedings of the 2009 International Conference on Management and Service Science (MASS), September 20-22, Wuhan. Yin, R. K. (2003). Case study research: Design and methods (3rd ed.). Newbury Park, CA: Sage Publications. 